DOI https://doi.org/10.30525/978-9934-588-79-2-2.6

\title{
ИСПОЛЬЗОВАНИЕ ПЛАТФОРМЫ АRDUINO ПРИ РАЗРАБОТКЕ МЕТОДА ИНФРАКРАСНОЙ ЭХО-ИМПУЛЬСНОЙ ДЕФЕКТОСКОПИИ
}

\author{
Рагулин С. В. \\ кандидат технических наук, \\ заведущий кафедрой авиационной техники \\ Летной академии \\ Национального авиационного университета \\ Ушаков В. В. \\ старший преподаватель кафедры авиационной техники \\ Летной академии \\ Национального авиационного университета \\ Шарабайко А. Н. \\ кандидат технических наук, \\ Летной академии \\ Национального авиационного университета \\ 2. Кропивниикий, Кировоградская область, Украина
}

Проведение экспериментов с целью подтверждения и уточнения эксплуатационных характеристик метода инфракрасной эхоимпульсной дефектоскопии [1], требует построения автоматизированного измерительного комплекса, который обеспечивал бы сбор экспериментальных данных, их предварительную обработку и отображение в удобной для оператора форме. Кроме того, необходимо обеспечить автоматизированное управление используемым при проведении экспериментов лабораторным стендом.

Современная номенклатура готовых измерительных устройств и отдельных электронных компонентов дает возможность создания такого автоматизированного комплекса. Однако это требует высокой инженерно-технической квалификации разработчиков, а также значительной затраты материальных ресурсов и времени. Готовые же универсальные измерительные платформы недостаточно гибки, дорогостоящи и требуют для своего размещения значительных площадей, а зачастую и специально обученного персонала.

Перечисленным выше требованиям к аппаратной платформе наиболее полно, на наш взгляд, отвечает платформа Arduino. Arduino 28 
открытая электронная платформа, отличающаяся простотой в использовании, универсальностью и относительной дешевизной по сравнению с ее аналогами. Открытое программное обеспечение и архитектура данной платформы дает возможность использовать ее для приема и передачи аналоговых и цифровых сигналов, преобразования сигналов при помощи встроенных цифро-аналоговых (ЦАП) и аналогоцифровых (АЦП) преобразователей, управления различными устройствами и обмена данными с компьютером при помощи различных интерфейсов. Более подробно структура и интерфейс данной платформы описаны в [2, 3].

В рамках разработки метода инфракрасной эхо-импульсной дефектоскопии создано экспериментальное устройство отработки метода и лабораторный стенд для проведения неразрушающего контроля стеклопластиков данным методом.

Задачи автоматизированного измерительного комплексав рамках исследований метода инфракрасной эхо-импульсной дефектоскопии с использованием лабораторного стенда сводятся к следующему:

1. Управление лабораторным стендом, в частности обеспечение перемещения исследуемого образца вдоль измерительной головки с точностью не хуже $\pm 0,1$ мм, надежную фиксацию подвижной платформы в любой момент при проведении контроля и возврат ее в исходную точку, принятую за «0» координат по командам с пульта управления стендом либо с персонального компьютера.

2. Прием, обработка, сохранение и передача на компьютер диагностического сигнала от инфракрасного эхо-импульсного дефектоскопа.Данная задача разделяется на несколько составляющих, а именно: прием и преобразование аналогового сигнала в цифровой, вычисление среднего уровня диагностического сигнала с целью фильтрации посторонних шумов, сохранение и передача уровня диагностического сигнала с привязкой к текущей координате по длине исследуемого образца, выдача полученного пакета данных на персональный компьютер.

При разработке системы управления лабораторным стендом учтены следующие требования:

1. Возможность контроля образцов материалов различных линейных размеров.

2. Автоматический останов подвижной платформы при достижении ею крайних положений при любом режиме работы стенда.

3. Возможность задания начальной точки перемещения подвижной платформы в любом месте в пределах диапазона перемещения 
платформы с обеспечением последующего автоматического возврата платформы в начальную точку.

4. Возможность задания скорости перемещения подвижной платформы.

5. Обеспечения двойного управления работой стенда (с пульта управления и непосредственно с персонального компьютера).

6. Обеспечение защиты от подачи некорректных команд стенду.

Для управления шаговым двигателем использован подключаемый программный модуль Stepper (разработчик RyanOrendorff). Пульт управления стендом представляет собой клавиатуру состоящую из 8 кнопок, также подключенных непосредственно к цифровым входам модуля Arduino UNO.

Для обеспечения связи с персональным компьютером используется интерфейс параллельного порта Arduino IDE. При помощи данного интерфейса обеспечена возможность выдачи стенду перечисленных выше команд, а также задания текущей длины исследуемого образца. Блок-схема управления лабораторным стендом приведена на рис. 1.

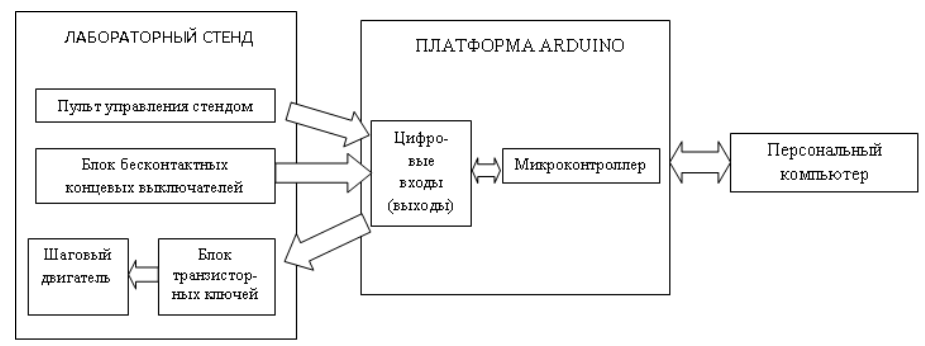

\section{Рис. 1. Блок-схема управления лабораторным стендом}

Особенностью созданного экспериментального устройства отработки метода инфракрасной эхо-импульсной дефектоскопии является то обстоятельство, что диагностическаяинформациявыдаваемая устройством представляет собой аналоговый сигнал, а именно напряжение постоянного тока изменяющееся в диапазоне от $0,1 \mathrm{~B}$ до 4,9 В. Таким образом для приема и последующей обработки диагностического сигнала необходимо преобразовать его в цифровую форму. Встроенный в платформу Arduino аналого-цифровой преобразователь (АЦП) с 10-битным разрешением и базовойскоростью опроса аналогового входа с частотой 500 Гц позволяет выполнять данную задачу с достаточной точностью. 
Блок-схема работы лабораторного стенда совместно с платформой Arduino в режиме обработки и передачи экспериментальных данных приведена на рис.2.

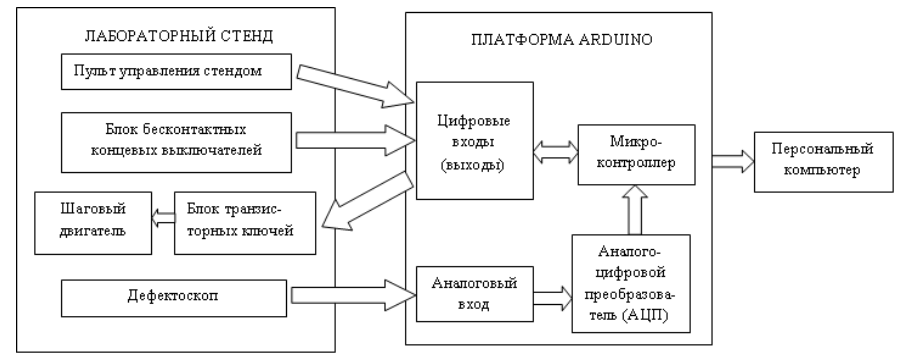

Рис. 2. Блок-схема работы системы в режиме обработки и передачи данных

Программный код приема, обработки и передачи данных реализован в бесконечном цикле «loop» скетча Arduino [2].

Для предварительной фильтрации диагностического сигнала производится вычисление среднего значения сигнала за 10 последних измерений. Полученные значения записываются в динамический массив в оперативной памяти платформы Arduino, который впоследствии передается на персональный компьютер и обрабатывается при помощи интерфейса PLX-DAQ, что дает возможность представления диагностической информации в табличной и графической форме, а также сохранения файла данных.

Выводы.

Использование платформы Arduino при создании автоматизированного измерительного комплекса в рамках исследования метода инфракрасной эхо-импульсной дефектоскопии позволяет решить задачи управления лабораторным оборудованием а также обработки и передачи экспериментальных данных с минимальными затратами материальных ресурсов и времени. Существенным преимуществом применения платформы Arduino является также простота окончательного монтажа оборудования.

Продемонстрирована возможность осуществления двойного управления лабораторным оборудованием, разработаны алгоритмы управления оборудованием и обработки экспериментальных данных с обеспечением необходимой точности. 


\title{
Литература:
}

1. Pusyryov. O.L. Development of Airframe Design Elements Control Technique under Operational Conditions / O.L. Pusyryov, V.O. Volkogon, O.M. Alekseev, V.V. Ushakov - Electronics and control systems, № 4 (50), 2016. C. 46-49.

2. Пономаренко В.И. Использование платформы Arduino в измерениях и физическом эксперименте/ В.И. Пономаренко, А.С. Караваев - Изв. вузов «ПНД», т. 22, № 4, 2014. С. 77-90.

3. Омельченко Е.Я. Краткий обзор и перспективы применения микропроцессорной платформы Arduino / Е.Я. Омельченко, В.О. Танич, А.С. Маклаков, Е.А. Карякина - «Электротехнические системы и комплексы», №. 21, 2013. С. 28-33.

4. Протасов А.Г. Универсальное устройство для сбора данных с аналоговых и цифровых преобразователей / А.Г. Протасов, А.С. Корогод, Е.Ф. Суслов - Вестник НТУУ «КПИ». Серия Приборостроение. 2015. - Вип. 49(1). С. 145-152.

DOI https://doi.org/10.30525/978-9934-588-79-2-2.7

\section{ВИКОРИСТАННЯ ІНТЕЛЕКТУАЛЬНИХ ТЕХНОЛОГІЙ ДЛЯ ПРОЩЕСУ ВИРОЩУВАННЯ ХЛІБОПЕКАРСЬКИХ ДРІЖДЖІВ}

\author{
Самойленко Ю. О. \\ кандидат технічних наук, \\ доиент кафедри автоматизаиії
}

та комп 'ютерних технологій систем управління

Національного університету харчових технологій

Савчук О. В.

кандидат технічних наук, старший викладач кафедри електропостачання імені професора В. М. Синькова Національного університету біоресурсів і природокористування України м. Київ, Україна

Сучасна теорія управління застосовується до широкого класу об'єктів, для яких розробляються системи автоматизації з властиво- 